\title{
The Effect of Different Symptom Experiences on Disease Outcome in Patients with Chronic Obstructive Pulmonary Disease: A Cluster Analysis
}

Wei-Chun Lin'1, PhD, RN, Tsuey-Yuan Huang², PhD, RN, Chieh-Yu Liü ${ }^{3}$ PhD, MD, Mei-Ling Yeh ${ }^{4}$, PhD, RN, Thomas Chang-Yao Tsao ${ }^{5}$, PhD, MD, Shu-Man Chen ${ }^{6}$, MSc, RN, Shiow-Li Hwang ${ }^{7 *}$, DNSc, RN.

${ }^{l}$ Department of Nursing, Min-Hwei Junior College of Health Care Management, Tainan, Taiwan.

${ }^{2}$ College of Nursing, Chang Gung University of Science and Technology, Taoyuan, Taiwan.

${ }^{3}$ College of Nursing, National Taipei University of Nursing and Health Sciences, Taipei, Taiwan.

${ }^{4}$ Graduate Institute of Integration of Traditional Chinese Medicine with Western Nursing, National Taipei University of Nursing and Health Sciences, Taipei, Taiwan.

${ }^{5}$ College of Medicine, Chung Shan Medical University, Taichung, Taiwan.

${ }^{6}$ Department of Nursing, National Taiwan University Hospital, Yunlin Branch, Yunlin, Taiwan.

${ }^{7}$ Department of Nursing, Asia University, Taichung, Taiwan.

Article Details

Article Type: Research Article

Received date: $09^{\text {th }}$ February, 2021

Accepted date: $15^{\text {th }}$ March, 2021

Published date: $23^{\text {th }}$ March, 2021

"Corresponding Author: Shiow-Li Hwang, DNSc, RN, Department of Nursing, Asia University, Taichung, No. 500, Lioufeng Rd., Wufeng, Taichung 41354, Taiwan, ROC. Taiwan. E-mail: slhwang2@gmail.com

Citation: Lin, W.C., Huang,T.Y., Liu, C.Y., Yeh, M.L., Tsao, C.Y., Chen, S.M., \& Hwang,S.L. (2021). The Effect of Different Symptom Experiences on Disease Outcome in Patients with Chronic Obstructive Pulmonary Disease: A Cluster Analysis. J Comp Nurs Res Care 6(1):172. doi: https://doi.org/10.33790/jenrc1100172.

Copyright: $\mathbb{C} 2021$, This is an open-access article distributed under the terms of the Creative Commons Attribution License 4.0, which permits unrestricted use, distribution, and reproduction in any medium, provided the original author and source are credited.

\section{Abstract}

Objectives: To explore whether subgroups of patients with chronic obstructive pulmonary disease (COPD) could be identified by their symptom experiences that form clusters and the impact of these symptom clusters on health outcome.

Background: Most patients with COPD experience numerous symptoms. However, few studies have investigated the symptom clusters and their effect on health outcome in patients with COPD.

Methods: A descriptive, cross-sectional study was conducted in a medical center. The subjects received specific questionnaires including the Memorial Symptom Assessment Scale, Clinical COPD Questionnaire, and Short Form-12 health survey. Hierarchical cluster analysis (HCA) was used to identify patient subgroups based on symptom experiences. Differences in psychological distress and health outcomes were evaluated using multivariate analysis of variance (MANOVA). Additionally, linear regressions were used to examine the prediction of health outcomes.

Results: Of the 139 subjects recruited for this study (mean age, 71.79 \pm 10.23 years), $95.7 \%$ were men. On average, patients with COPD experienced 6.71 symptoms. HCA was used to derive a three-cluster solution based on the 18 physical symptoms. MANOVA revealed significant mean differences in psychological distress scores between the three subgroups. Linear regression also revealed that the symptom cluster was able to explain $41.5 \%$ of variance in the total scores of CCQ and $51.1 \%$ of variance in the total scores of SF-12.

Conclusions: The symptoms experiences of patients with COPD are complex. Patients with high physical symptoms had the highest psychological distress and poorest HRQOL. The symptom experiences affect the overall quality of life, and the HRQOL in turn affects the symptom clusters. For patients with COPD, the symptom assessment should be multidimensional, based on the concept of symptom clusters. These findings provide a foundation for symptom management and nursing interventions to improve the health status of patients with COPD.

Keywords: chronic obstructive pulmonary disease (COPD); symptom cluster; psychological distress; health-related quality of life (HRQOL)

\section{Introduction}

According to the World Health Organization, chronic obstructive pulmonary disease (COPD)is the third leading cause of death worldwide [1]. Patients with COPD experience multiple symptoms that commonly cause systemic consequences $[2,3]$. Most patients with COPD experience not only dyspnoea but also one or more symptoms associated with the respiratory tract, such as cough, phlegm, and wheezing [4]. A previous study has indicated that the distress and burden from symptoms experienced by patients with COPD are similar to those of patients with cancer; nevertheless, patients with COPD tend to live longer [5]. Symptoms affect not only the physiological status but also the functional status and emotional changes in patients with COPD [5-7].

To date, studies on the symptoms of patients with COPD have focused on single symptoms, especially dyspnoea $[8,9]$. However, COPD causes systemic consequences that change the structure and function of the lungs and other organs of patients [10], and most patients experience multiple symptoms simultaneously [4,11-13]. These symptoms may interact with others and form a "symptom cluster" that affects the functional status and health-related quality of life (HRQOL) [14,15].

Two approaches have been used in symptom cluster research. The first approach involves grouping symptoms by using a cluster analysis or factor analysis. The advantage of this method is that it allows the identification of symptoms in a cluster set and offers a reference for symptom assessment [16-18]. The second approach involves grouping subjects based on differences in symptom experiences by using a cluster analysis, and determining the differences in demographic and clinical characteristics and health outcomes between subgroups. The advantage of this method is that it allows for the identification of patients who may be at risk of poorer outcomes. This approach would also enable healthcare providers to develop symptom management strategies and provide early clinical interventions to improve the prognosis according to the symptom cluster [19-20]. 
On average, patients with moderate-to-sever COPD experienced 3.3 to 11 symptoms [11-13]. Studies have shown that among the symptoms of distress in patients with severe COPD, dyspnoea is the most common with a high prevalence. Other symptoms with high prevalence were fatigue, xerostomia, cough, and anxiety [21]. As the disease progresses, the number and frequency of symptoms increased, and finally affect the patient's physical function and social abilities [22]. Most of patients with COPD experienced fatigue, and is affected by respiratory symptoms [23]. Dyspnoea and its consequences affect a patient's physical comfort. The most common discomforts are the barriers to physical activity and activity intolerance, which increase according to the severity of disease. The consequences of dyspnoea also limit life activities, and some related studies have shown that patients with COPD experience the biggest limitations in performing basic daily activities [24-26].

In addition to the physical status, the psychological status of a patient is also affected in dyspnoea. Studies have shown that patients with COPD often suffered from depression, anxiety, scare, and panic $[25,27]$. Patients with COPD accompanying dyspnoea exhibit anxiety and fear of emotions, are frustrated and tired, and even show the loss of social activities. Furthermore, studies have shown that the symptoms and accompanying consequences experienced by the majority of patients with COPD, with the exception of dyspnoea, are similar to those experienced by patients with cancer [4, 5, 27].

The purposes of this study were to explore whether the subgroups of patients with COPD could be identified on the basis of their symptom experiences that form clusters, and to assess the impact of these clusters on the patients' HRQOL.

\section{Methods}

\section{Study design and participant selection}

A descriptive, cross-sectional study was conducted using self-report structured questionnaires to obtain information from a convenience sample of outpatients with COPD at the Pulmonary Clinic of the Department of Internal Medicine at a medical centre in Central Taiwan.

The sample size needed for this study was estimated based on multivariate analysis of variance (MANOVA) assuming global effects (f2) equal to be medium $=0.15$, type $I$ error $(\alpha)=0.05$ and power $=80 \%$, and taking into account 37 variables which will be used in cluster analysis (13 variables in Table 1, 24 symptoms in Table 2). By using the $G^{*}$ power ver 3.1, the adequate sample size for this study was estimated to be 147 subjects. A diagnosis of COPD was confirmed according to a patient's respiratory symptoms (dyspnoea, chronic cough, or sputum production), history of exposure to risk factors of COPD, and airflow limitation confirmed by the spirometry test. The diagnosis was on the basis of the GOLD criteria [3] designed by a thoracic physician.

The inclusion criteria included a spirometry test after bronchodilation with a FEV1/FVC ratio lower than 0.70 . Pulmonary function predicted values were obtained from the multiethnic reference values for spirometry of the European Respiratory Society Global Lung Function Initiative [28]. The exclusion criteria included pulmonary tuberculosis, lung cancer, or cancer of other organs under active treatment; major organ failure such as chronic renal failure, for which the patient is under going haemodialysis; heart failure with the left ventricular ejection fraction less than $40 \%$; cirrhosis of the infection, urinary tract infection, or gastrointestinal infection, in the past week; or an exacerbation of COPD in the past week. The exacerbation of COPD is an acute event characterized by a worsening of the patient's respiratory symptoms that is beyond the normal dayto-day variations and leads to a change in medication, according to the GOLD criteria [3].

The potential participants were approached form COPD case management database, there are total 243 subjects, 56 not met inclusion criteria, and 48 refused to participate (Figure 1).

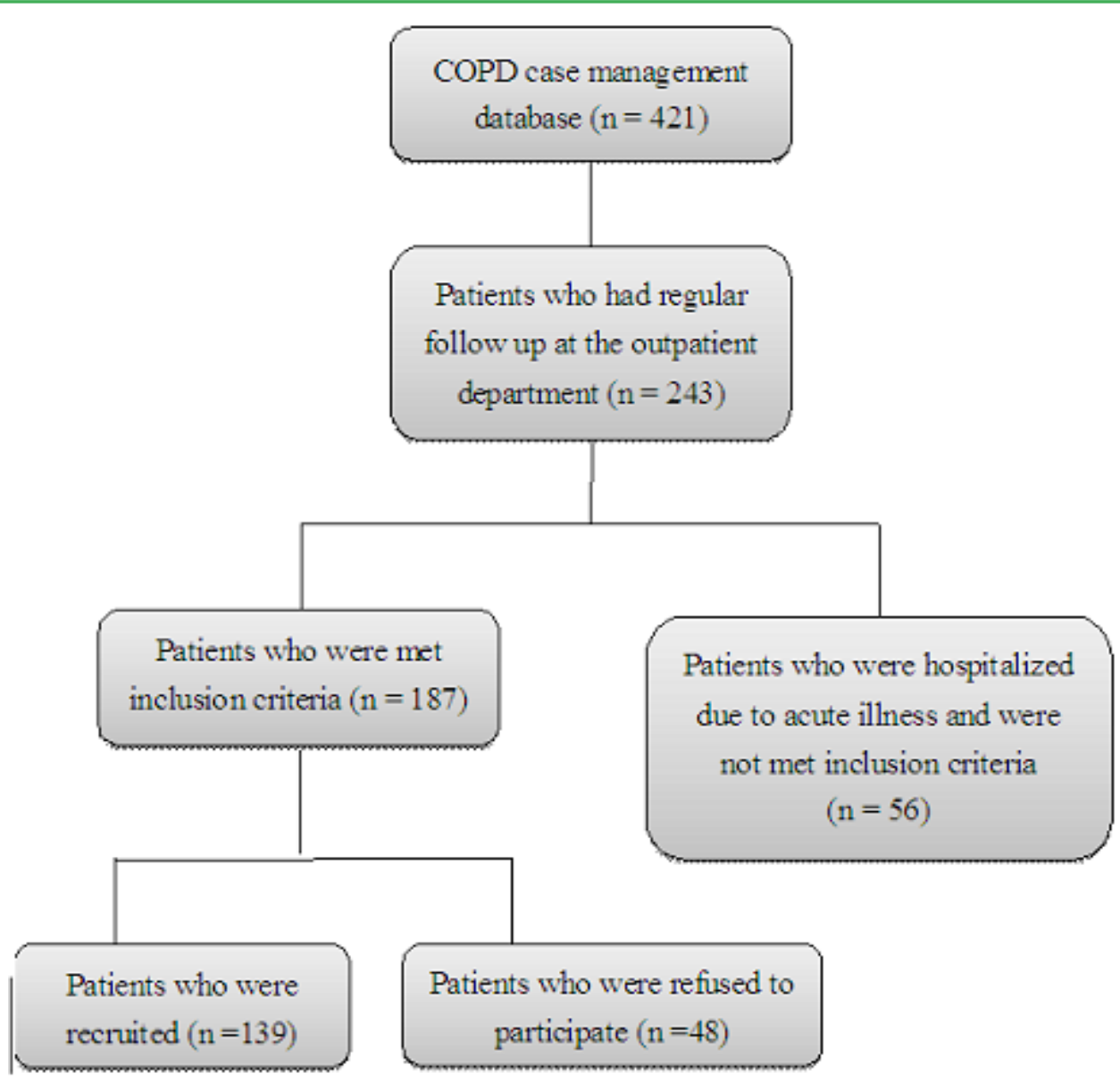

Figure 1. Flow chart for study sample 


\section{Data collection}

This study was approved by the Institutional Review Board of the medical centre. The researcher presented the purpose of the study to all the participants, and they completed the informed consent forms before data collection.

After completing the section of the questionnaire for collecting their demographic information and medical history, the participants completed the self-administered version of three questionnaires including the Memorial Symptom Assessment Scale (MSAS), the Clinical COPD Questionnaire (CCQ), and the 12-item Short Form Health Survey (SF-12).

\section{Instruments}

\section{Demographic and clinical characteristics}

Demographic and clinical characteristics included age, sex, marital status, life status, smoking habits, medication, self-reported comorbidities, lung function, and GOLD group. GOLD grouping the severity of COPD were according to symptom that assessed by modified Medical Research Council (mMRC) dyspnea scale, risk that assessed by GOLD classification of airflow limitation, and exacerbation history. Group A and $\mathrm{C}$ had slighter symptoms, low and high-risk of exacerbation, respectively. Group B and D had greater symptoms, low and high-risk of exacerbation, respectively. The grouping was performed by a thoracic physician.

\section{Symptoms}

The symptoms were assessed using the MSAS, which is a multidimensional symptom profile developed by Portenoy and colleagues [29] for measuring the symptom burden of patients with cancer. The original version of MSAS measures the prevalence (yes or no) of 32 symptoms (26 physical and six psychological symptoms) during the past week. Whenever a symptom was present, the symptom was assessed using the dimensions of frequency (1 = rarely to $4=$ almost constantly) for 24 symptoms, severity $(1=$ slight to $4=$ very severe $)$, and distress $(1=$ not at all to $4=$ very much) for 32 symptoms. Higher scores represent greater frequency, severity, and distress. A score for each symptom is the average score for calculating the frequency, severity, and distress dimensions that is defined as an MSAS symptom burden score. If a subject indicated they did not experience a symptom, there is no rating of this symptom. The MSAS has three subscales: the physical subscale (MSAS-PHYS) and psychological subscale (MSAS-PSYCH), which are the average symptom scores of all the physical and psychological symptoms, respectively. The global distress index (MSAS-GDI) is the average score of 10 symptoms, including the frequency of feeling sad, worrying, feeling nervous, and feeling irritable, and the distress from the lack of energy, pain, dry mouth, lack of appetite, feeling drowsy, and constipation. The total MSAS score is the average score of all 32 symptoms [29].

MSAS is a valid and reliable instrument that has been used on patients with COPD $[11,12,21]$. The Chinese version of MSAS also has adequate psychometric validity and reliability [30]. Because of the cultural differences between the study populations in this study and previous studies, the content validity of the Chinese version of MSAS was assessed by six experts before data collection. According to the experts' rating, we deleted six symptoms included nausea, vomiting, diarrhea, problems with sexual interest or activity, difficulty swallowing and hair loss that did not reach the standard value of the item content validity index (CVI) [31].Finally, 18 physical symptoms, six psychological symptoms, and two body image symptoms were included in the survey.The CVIin this study was as follows: 0.96 for scale-CVI, and 0.83 to 1.0 for item-CVI. Cronbach's alpha coefficient in this study was 0.89 for the total MSAS score. The internal consistencies of the MSAS-PHYS and MSAS-PSYCH were 0.84 and 0.82 , respectively.

\section{Psychological distress}

Psychological distress was assessed using the MSAS-PSYCH that included six psychological symptoms (difficulty sleeping, difficulty concentrating, feeling sad, worrying, feeling nervous, and feeling irritable). Psychological distress was the mean score of all the psychological symptoms, with higher scores representing greater psychological distress [29].

\section{Health-Related Quality of Life CCQ}

The CCQ was developed to measure the health status of patients with COPD. The CCQ measured the impact of COPD, not only regarding the airway symptoms but also the activity limitation and emotional dysfunction. The CCQ has three domains: symptoms (4 items), functional state (4 items), and mental state ( 2 items). The scores rate the frequency of symptoms such as shortness of breath, cough, and producing phlegm. Also rate the frequency of emotional status such as concerning breathing is getting worse and depressed. Furthermore, it can rate the degree of limitations of physical activities and social activities. All scores range from 0 (no impairment) to 6(total impairment), and the main outcome measure of the CCQ is the average score of 10 items, with higher scores representing a worse health status and quality of life [32].

The Chinese version of the CCQ has excellent psychometric validity and reliability [33]. Cronbach's alpha coefficient in this study was 0.89 for the total score of the CCQ. The internal consistencies of the symptoms, functional state, and mental state were $0.74,0.82$, and 0.87 , respectively.

\section{SF-12}

The SF-12 was simplified from the 36-item Short Form Health Survey and developed for measuring generic HRQOL. The SF12 consists of eight domains: physical functioning, role limitation because of physical problems, bodily pain, general health, vitality, social functioning, role limitation because of emotional problems, and mental health. The scores range from 0 to 100, with higher scores indicating a more favourable health status [34]. Cronbach's alpha coefficient in this study was 0.87 for the total score of the SF-12.

\section{Statistical analysis}

The statistical analysis was performed using PASW Statistics for Windows / Macintosh, Version 18.0 (SPSS Inc., Chicago, IL, USA). The continuous variables are expressed as means and standard deviation (SD). Categorical variables are expressed as frequency and percentage. Descriptive statistics were performed to describe participant characteristics.

To determine the number of subgroups of participants, the hierarchical cluster analysis was first applied and the k-meanscluster analyses were adopted to validate to the clustering the participants. In hierarchical cluster analysis (HCA), we used Ward's minimum variance method that pooled the within-cluster sum of squares or error sum of squares based on minimized sum of squares [35]. The resulted clusters were determined using dendrograms, and which were incorporated with clinical experts' opinions. Secondly, by using the cluster centers obtained from the previous HCA, the k-means cluster analysis was further used to verify and adjust the resulted clustering: the patients were reallocated based on the HCA cluster centers to see if all the patients were correctly clustered as HCA's clusters.

In addition, the one-way analysis of variance (ANOVA)and chisquare test were used to determine whether significant differences existed between the subgroups of participants in demographic, clinical characteristics, and comorbidities. HRQOL scores were tested jointly for differences in mean scores among subgroups by using MANOVA, followed by individual ANOVA. Post-hoc contrasts were determined using Scheffe's method.

Linear regressions were used to examine the prediction of health outcomes and the correlations between the symptom clusters (subgroup variables) and health outcomes. Initially, we set the high physical symptom cluster (subgroup1) as the reference group and created two dummy variables, namely, PHY1 (subgroup 2 moderate physical symptom cluster compared with subgroup 1 high physical symptom cluster) and PHY2 (subgroup 3 low physical symptom cluster compared with subgroup 1 high physical symptom cluster). Statistical significance was set at $p<0.05$. 


\section{Results}

\section{Participant characteristics}

Of the 139 participants who completed the study (mean age,
$71.79 \pm 10.23), 95.7 \%$ were men. The demographic and clinical characteristics of this study population are given in Table 1.

\begin{tabular}{|c|c|c|c|c|c|}
\hline & $\begin{array}{l}\text { All sample } \\
(\mathrm{n}=139)\end{array}$ & $\begin{array}{l}\text { Subgroup } 1 \\
(\mathrm{n}=26,18.7 \%)\end{array}$ & $\begin{array}{l}\text { Subgroup } 2 \\
(\mathrm{n}=53,38.1 \%)\end{array}$ & $\begin{array}{l}\text { Subgroup } 3 \\
(\mathrm{n}=60,43.2 \%)\end{array}$ & \\
\hline Characteristics & Mean \pm SD & Mean \pm SD & Mean \pm SD & Mean \pm SD & $\mathrm{F}$ \\
\hline Age (years) & $71.79 \pm 10.23$ & $69.69 \pm 9.23$ & $73.70 \pm 10.39$ & $71.02 \pm 10.37$ & 1.66 \\
\hline BMI (kg/m2) & $24.18 \pm 4.05$ & $25.61 \pm 4.61$ & $23.38 \pm 4.22$ & $24.29 \pm 3.51$ & 2.68 \\
\hline FEV1/FCV & $57.28 \pm 10.98$ & $57.54 \pm 12.26$ & $53.90 \pm 11.54$ & $60.16 \pm 9.07$ & $4.84 *$ \\
\hline \multirow[t]{3}{*}{ FEV1\% } & $59.94 \pm 17.92$ & $64.58 \pm 24.86$ & $54.86 \pm 15.74$ & $62.42 \pm 15.23$ & $3.72 *$ \\
\hline & $\begin{array}{l}\text { All sample } \\
(\mathrm{n}=139)\end{array}$ & $\begin{array}{l}\text { Subgroup 1 } \\
(\mathrm{n}=26,18.7 \%)\end{array}$ & $\begin{array}{l}\text { Subgroup 2 } \\
(\mathrm{n}=53,38.1 \%)\end{array}$ & $\begin{array}{l}\text { Subgroup 3 } \\
(\mathrm{n}=60,43.2 \%\end{array}$ & \\
\hline & $\mathrm{n} \quad(\%)$ & n (\%) & n (\%) & n (\%) & $\mathrm{X} 2$ \\
\hline Sex & & & & & 4.76 \\
\hline male & $133(95.7)$ & $24(92.3)$ & $49(92.5)$ & $60(100)$ & \\
\hline female & $6(4.3)$ & $2(7.7)$ & $4(7.5)$ & $0(0)$ & \\
\hline GOLDGroups & & & & & $28.51 * * *$ \\
\hline Group A & $64(46.0)$ & $6(23.1)$ & $18(34.0)$ & $40(66.7)$ & \\
\hline Group B & $29(20.9)$ & $10(38.4)$ & $13(24.5)$ & $6(10.0)$ & \\
\hline Group C & $19(13.7)$ & $4(15.4)$ & $5(9.4)$ & $10(16.7)$ & \\
\hline Group D & $27(19.4)$ & $6(23.1)$ & $17(32.1)$ & $4(6.7)$ & \\
\hline Smoking habits & & & & & 5.369 \\
\hline Ex-smokers & $81(58.3)$ & $14(53.9)$ & $36(67.9)$ & $31(51.7)$ & \\
\hline Smokers & $42(30.2)$ & $9(34.6)$ & $10(18.9)$ & $23(38.3)$ & \\
\hline Non-smokers & $16(11.5)$ & $3(11.5)$ & $7(13.2)$ & $6(10.0)$ & \\
\hline \multicolumn{6}{|l|}{ Comorbidity } \\
\hline Hypertension & $49(35.3)$ & $11(42.3)$ & $13(24.5)$ & $25(41.7)$ & 4.32 \\
\hline GIdisease & $23(16.5)$ & $4(15.4)$ & $15(28.3)$ & $4(6.7)$ & $9.57 *$ \\
\hline Diabetes & $18(12.9)$ & $6(23.1)$ & $5(9.4)$ & 7 (11.7) & 3.03 \\
\hline Heart disease & $18(12.9)$ & $6(23.1)$ & $6(10.7)$ & $6(10.0)$ & 2.95 \\
\hline Neurological & $16(11.5)$ & $1(3.8)$ & $10(18.9)$ & $5(8.3)$ & 4.91 \\
\hline Urinary disease & $11 \quad(7.9)$ & $(7.7)$ & $6(10.7)$ & $3(5.0)$ & 1.55 \\
\hline Arthritis & $(7.9)$ & $6(23.1)$ & $4(7.5)$ & $1(1.7)$ & $11.24 *$ \\
\hline Liver disease & $(5.0)$ & $(3.8)$ & (9.4) & $1(1.7)$ & $6.08 *$ \\
\hline Stroke & $(4.3)$ & $(3.8)$ & $(7.5)$ & $1(1.7)$ & 4.63 \\
\hline Renal disease & $(3.6)$ & $(3.8)$ & $(5.7)$ & $1(1.7)$ & 3.33 \\
\hline \multicolumn{6}{|c|}{$\begin{array}{l}{ }^{*} \mathrm{p}<0.05 ; * * \mathrm{p}<0.01 ; \mathrm{SD}, \text { standard deviation; BMI, body mass index; X2, } \\
\text { chi-square;GOLD, Global Initiative for Chronic Obstructive Lung Disease; Group A: Low risk \& less symptoms; } \\
\text { Group B: Low risk \& more symptoms; Group C: High risk \& less symptoms; Group D: High risk \& more } \\
\text { symptoms;Subgroup 1: high physical symptom cluster; Subgroup 2: moderate physical symptom cluster; Subgroup } \\
\text { 3: low physical symptom cluster; GI,Gastrointestinal. }\end{array}$} \\
\hline
\end{tabular}

Table 1. Demographic and clinical characteristics of all sample and differences among three subgroups

\section{Cluster analysis}

Two, three, and four clusters were examined in the HCA. We found three distinctive cluster based on 18 physical symptoms. As illustrated in Figure 2, with the two-cluster solution, $24.5 \%$ of the sample $(\mathrm{n}=34)$ was categorized in the 'high physical symptom' cluster and $75.5 \%$ of the sample $(n=105)$ was categorized in the 'low-to-moderate physical symptom' cluster. When classifications were based on the three-cluster solution, the 'high physical symptom' cluster remained intact, and the 'low-to-moderate physical symptom' cluster was divided into two groups; $36.0 \%$ of the sample $(\mathrm{n}=50)$ was categorized in the "moderate physical symptom' cluster and 39.5\% $(\mathrm{n}=55)$ in the 'low physical symptom' cluster. Then, k-means cluster analysis was used to verify and adjust the clustering based on the three-cluster solution of the HCA. Finally, $18.7 \%$ of the sample $(n=26)$ was categorized in the 'high physical symptom' cluster (subgroup 1), 38.1\% $(\mathrm{n}=53)$ in the 'moderate physical symptom' cluster (subgroup 2), and $43.2 \%(n=60)$ in the 'low physical symptom' cluster (subgroup 3).

\section{Differences in the demographic and clinical characteristics}

Table 1 summarizes the demographic and clinical characteristics of all patients and for the three subgroups. No significant differences 


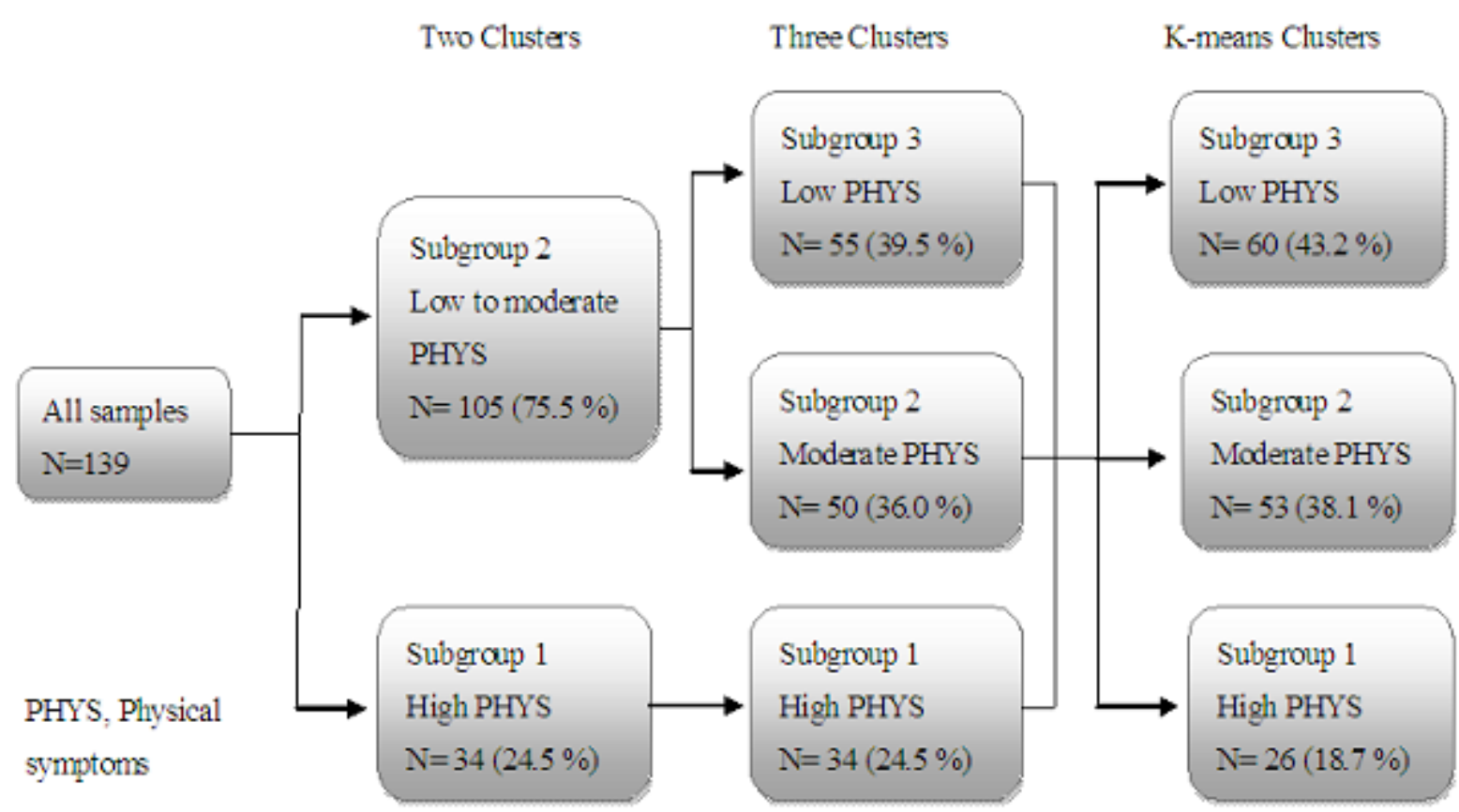

Figure 2. Distribution of participants subgroups based on hierarchical and k-means cluster analysis

in demographic characteristics were observed among the three subgroups. Among the clinical characteristics, significant differences were observed in the lung function (FEV1/FVC, FEV1\%) parameters, but the post-hoc contrasts revealed no significant difference among the three subgroups in FEV1\% (all p > 0.05). A chi-square test revealed significant differences in disease severity based on the GOLD groups among the three subgroups (X2 $=28.51, \mathrm{p}<0.001)$. The individual group differencesin disease severity revealed that participants in the high physical symptom cluster (subgroup 1) and in the moderate physical symptom cluster (subgroup 1) had significantly higher severity than the participants in the low physical symptom cluster (subgroup 3) (all p < 0.001). No significant differences were found among the three subgroups in any comorbidities except gastrointestinal disease $(\mathrm{X} 2=9.57, \mathrm{p}=0.008)$, arthritis $(\mathrm{X} 2=11.24$, $\mathrm{p}=0.004)$, and liver disease $(\mathrm{X} 2=6.08, \mathrm{p}=0.048)$.

\section{Differences in physical symptom scores}

Physical symptoms with the highest prevalence were cough (91\%), lack of energy (61\%), and shortness of breath (59\%). Other symptoms with high prevalence were dry mouth $(38 \%)$, pain (37\%), constipation $(32 \%)$, and feeling drowsy $(31 \%)$. The mean number of symptoms for a participant was $6.71 \pm 4.79$. For the participants, the physical symptoms such as pain, lack of energy, itching, and shortness of breath were particularly distressful. In addition, the highest frequency of symptoms was lack of energy, followed by dry mouth and itching. Furthermore, lack of energy was also the highest severity of symptoms followed by pain and feeling drowsy. Table 2 summarizes the symptom scores for the three subgroups. Participants in subgroup 1 had worse physical symptoms than did those in subgroups 2 and 3 . Significant mean differences were observed in all physical symptom scores among the three subgroups (all $\mathrm{p}<0.05$ ). In addition, the posthoc contrasts revealed that participants in the high physical symptom cluster (subgroup 1) had significantly higher symptom scores than the participants in the moderate physical symptom cluster (subgroup 2) and in the low physical symptom cluster (subgroup 3) (all p < $0.05)$.

\begin{tabular}{|c|c|c|c|c|c|}
\hline \multicolumn{6}{|c|}{ MSAS Symptom Score } \\
\hline & $\begin{array}{l}\text { All sample } \\
(\mathrm{n}=139)\end{array}$ & $\begin{array}{l}\text { Subgroup } 1 \\
(\mathrm{n}=26,18.7 \%)\end{array}$ & $\begin{array}{l}\text { Subgroup } 2 \\
(\mathrm{n}=53,38.1 \%)\end{array}$ & $\begin{array}{l}\text { Subgroup } 3 \\
(\mathrm{n}=60,43.2 \%)\end{array}$ & \\
\hline & Mean \pm SD & Mean \pm SD & Mean \pm SD & Mean \pm SD & $\mathrm{F}$ \\
\hline \multicolumn{6}{|c|}{ Physical Symptom } \\
\hline Cough & $1.25 \pm 0.62$ & $1.48 \pm 0.96$ & $1.30 \pm 0.47$ & $1.09 \pm 0.53$ & $4.01^{*}$ \\
\hline Lack of energy & $1.00 \pm 0.96$ & $2.07 \pm 0.98$ & $1.32 \pm 0.62$ & $0.25 \pm 0.46$ & $82.68^{* * *}$ \\
\hline $\begin{array}{l}\text { Shortness of } \\
\text { breath }\end{array}$ & $0.91 \pm 0.91$ & $1.78 \pm 1.14$ & $1.10 \pm 0.67$ & $0.37 \pm 0.55$ & $36.02^{* * *}$ \\
\hline Dry mouth & $0.58 \pm 0.85$ & $1.73 \pm 1.00$ & $0.48 \pm 0.61$ & $0.18 \pm 0.43$ & $55.52^{* * *}$ \\
\hline Pain & $0.60 \pm 0.88$ & $1.45 \pm 1.08$ & $0.77 \pm 0.82$ & $0.08 \pm 0.31$ & $35.13^{* * *}$ \\
\hline Constipation & $0.44 \pm 0.68$ & $0.63 \pm 0.84$ & $0.15 \pm 0.37$ & $0.06 \pm 0.26$ & $16.49^{* * *}$ \\
\hline Feeling drowsy & $0.49 \pm 0.83$ & $1.57 \pm 1.14$ & $0.46 \pm 0.58$ & $0.04 \pm 0.22$ & $55.07^{* * *}$ \\
\hline $\begin{array}{l}\text { Problems with } \\
\text { urination }\end{array}$ & $0.41 \pm 0.71$ & $0.78 \pm 1.01$ & $0.55 \pm 0.71$ & $0.13 \pm 0.35$ & $10.83^{* * *}$ \\
\hline
\end{tabular}

Table. 2 to be Cont.... 


\begin{tabular}{|c|c|c|c|c|c|}
\hline Numbness/tingling in hands/feet & $0.41 \pm 0.71$ & $1.17 \pm 1.19$ & $0.50 \pm 0.64$ & $0.05 \pm 0.26$ & $26.45^{* * *}$ \\
\hline Lack of appetite & $0.30 \pm 0.56$ & $0.76 \pm 0.78$ & $0.39 \pm 0.55$ & $0.02 \pm 0.12$ & $22.82^{* * *}$ \\
\hline Dizziness & $0.31 \pm 0.59$ & $0.84 \pm 0.79$ & $0.35 \pm 0.59$ & $0.04 \pm 0.22$ & $21.81^{* * *}$ \\
\hline Feeling bloated & $0.28 \pm 0.66$ & $0.93 \pm 1.01$ & $0.23 \pm 0.46$ & $0.05 \pm 0.30$ & $21.33^{* * *}$ \\
\hline Itching & $0.25 \pm 0.64$ & $0.80 \pm 1.01$ & $0.17 \pm 0.52$ & $0.08 \pm 0.31$ & $14.53^{* * *}$ \\
\hline Weight loss & $0.19 \pm 0.48$ & $0.57 \pm 0.80$ & $0.15 \pm 0.37$ & $0.06 \pm 0.26$ & $12.40^{* * *}$ \\
\hline Change in the way food tastes & $0.13 \pm 0.39$ & $0.22 \pm 0.57$ & $0.21 \pm 0.46$ & $0.00 \pm 0.00$ & $6.02^{*}$ \\
\hline Swelling of arms or legs & $0.10 \pm 0.47$ & $0.15 \pm 0.42$ & $0.19 \pm 0.50$ & $0.01 \pm 0.12$ & $3.37^{*}$ \\
\hline Sweats & $0.08 \pm 0.33$ & $0.21 \pm 0.53$ & $0.09 \pm 0.34$ & $0.02 \pm 0.15$ & $3.10^{*}$ \\
\hline Mouth sores & $0.10 \pm 0.47$ & $0.34 \pm 0.92$ & $0.06 \pm 0.25$ & $0.04 \pm 0.28$ & $4.23^{*}$ \\
\hline MSAS-PHYS total score & $0.44 \pm 0.33$ & $0.97 \pm 0.27$ & $0.50 \pm 0.15$ & $0.14 \pm 0.09$ & $250.5^{* * *}$ \\
\hline \multicolumn{6}{|l|}{ Psychological Symptoms } \\
\hline Difficulty concentrating & $0.59 \pm 1.00$ & $1.09 \pm 1.04$ & $0.39 \pm 0.58$ & $0.05 \pm 0.25$ & $28.04^{* * *}$ \\
\hline Difficulty sleeping & $0.38 \pm 0.75$ & $1.27 \pm 1.48$ & $0.54 \pm 0.75$ & $0.34 \pm 0.80$ & $8.82^{* * *}$ \\
\hline Feeling sad & $0.37 \pm 0.84$ & $1.15 \pm 1.21$ & $0.37 \pm 0.55$ & $0.04 \pm 0.22$ & $27.54^{* * *}$ \\
\hline Worrying & $0.33 \pm 0.75$ & $1.33 \pm 1.38$ & $0.26 \pm 0.51$ & $0.05 \pm 0.28$ & $31.79^{* * *}$ \\
\hline Feeling irritable & $0.17 \pm 0.61$ & $0.70 \pm 1.17$ & $0.07 \pm 0.28$ & $0.03 \pm 0.24$ & $14.75^{* * *}$ \\
\hline Psychological distress & $0.37 \pm 0.57$ & $1.12 \pm 0.86$ & $0.31 \pm 0.32$ & $0.09 \pm 0.19$ & $50.83^{* * *}$ \\
\hline \multicolumn{6}{|c|}{$\begin{array}{l}\text { The MSAS symptom score is the average of the scores on the frequency, severity, and distress scale for each } \\
\text { symptom. } \\
{ }^{*} \mathrm{p}<0.05 ;{ }^{* *} \mathrm{p}<0.01 ;{ }^{* * *} \mathrm{p}<0.001 ; \mathrm{SD} \text {, standard deviation; MSAS-PHYS, Memorial Symptom Assessment Scale- } \\
\text { Physical Symptoms; Subgroup 1: high physical symptom cluster; Subgroup 2: moderate physical symptom cluster; } \\
\text { Subgroup 3: low physical symptom cluster. }\end{array}$} \\
\hline
\end{tabular}

Table 2. Comparison of physical and psychological symptom scores among three subgroups

\section{Differences in the HRQOL}

Significant mean differences were observed in each domain of both the CCQ and SF-12 HRQOL scores in the MANOVA (Wilk's lambda value $=0.27, F=10.61, p<0.001)$. Subsequently, significant differences were explored separately for the CCQ and SF-12 scores by using ANOVA. Significant mean differences were observed among the three subgroups in the symptom domain $(\mathrm{F}=40.75, \mathrm{p}<0.001)$, functional state $(\mathrm{F}=25.47, \mathrm{p}<0.001)$, mental state $(\mathrm{F}=30.66, \mathrm{p}<0.001)$, and total scores of the CCQ $(\mathrm{F}=48.28, \mathrm{p}<0.001)$. Additionally, significant mean differences were observed in each domain of the SF-12: physical functioning $(\mathrm{F}=25.09, \mathrm{p}<0.001)$, role limitation because of physical problem $(\mathrm{F}=13.42, \mathrm{p}<0.001)$, role limitation because of emotional problem $(\mathrm{F}=23.24, \mathrm{p}<0.001)$, vitality $(\mathrm{F}$ $=78.52, \mathrm{p}<0.001)$, mental health $(\mathrm{F}=24.81, \mathrm{p}<0.001)$, social functioning $(\mathrm{F}=27.32, \mathrm{p}<0.001)$, pain $(\mathrm{F}=17.25, \mathrm{p}<0.001)$, and general health $(\mathrm{F}=33.25, \mathrm{p}<0.001)$. The results and post-hoc contrasts are presented in Table 3 .

\begin{tabular}{|c|c|c|c|c|c|}
\hline & $\begin{array}{l}\text { Subgroup } 1 \\
(\mathrm{n}=26,18.7 \%)\end{array}$ & $\begin{array}{l}\text { Subgroup } 2 \\
(\mathrm{n}=53,38.1 \%)\end{array}$ & $\begin{array}{l}\text { Subgroup } 3 \\
(\mathrm{n}=60,43.1 \%)\end{array}$ & & Post Hoc \\
\hline HRQOL & Mean \pm SD & Mean \pm SD & Mean \pm SD & $\mathrm{F}$ & contrast \\
\hline \multicolumn{6}{|l|}{ CCQ } \\
\hline Symptom & $2.08 \pm 1.01$ & $1.39 \pm 0.61$ & $0.74 \pm 0.46$ & $40.75^{* * *}$ & $\begin{array}{l}1>2, P<0.001 \\
1>3, P<0.001 \\
2>3, P<0.001\end{array}$ \\
\hline Functional state & $1.86 \pm 1.13$ & $1.46 \pm 0.98$ & $0.58 \pm 0.54$ & $25.74^{* * *}$ & $\begin{array}{l}1>3, P<0.001 \\
2>3, P<0.001\end{array}$ \\
\hline Mental state & $2.06 \pm 1.60$ & $1.08 \pm 0.99$ & $0.25 \pm 0.47$ & $30.66^{* * *}$ & $\begin{array}{l}1>2, P<0.001 \\
1>3, P<0.001 \\
2>3, P<0.001\end{array}$ \\
\hline Total score & $1.98 \pm 0.97$ & $1.36 \pm 0.66$ & $0.58 \pm 0.42$ & $48.28^{* * *}$ & $\begin{array}{l}1>2, P<0.001 \\
1>3, P<0.001 \\
2>3, P<0.001\end{array}$ \\
\hline SF-12 & & & & & \\
\hline
\end{tabular}

Table. 3 to be Cont... 


\begin{tabular}{|c|c|c|c|c|c|}
\hline Physical & $29.8 \pm 30.8$ & $42.5 \pm 19.4$ & $65.0 \pm 22.6$ & $25.09^{* * *}$ & $1<3, \mathrm{P}<0.001$ \\
\hline functioning & & & & & $2<3, \mathrm{P}<0.001$ \\
\hline Role physical & $51.9 \pm 49.9$ & $56.6 \pm 49.1$ & $91.7 \pm 28.9$ & $13.42^{* * *}$ & $\begin{array}{l}1<3, \mathrm{P}<0.001 \\
2<3, \mathrm{P}<0.001\end{array}$ \\
\hline Role emotional & $53.4 \pm 39.3$ & $77.1 \pm 34.6$ & $97.5 \pm 11.0$ & $23.24^{* * * *}$ & $\begin{array}{l}1<2, \mathrm{P}=0.003 \\
1<3, \mathrm{P}<0.001 \\
2<3, \mathrm{P}=0.001\end{array}$ \\
\hline Vitality & $41.5 \pm 26.5$ & $73.2 \pm 22.5$ & $96.0 \pm 8.1$ & $78.52^{* * *}$ & $\begin{array}{l}1<2, \mathrm{P}<0.001 \\
1<3, \mathrm{P}<0.001 \\
2<3, \mathrm{P}<0.001 \\
4<2, \mathrm{P}<0.001\end{array}$ \\
\hline Mental health & $70.8 \pm 26.8$ & $86.2 \pm 11.8$ & $96.0 \pm 10.8$ & $24.81^{* * *}$ & $\begin{array}{l}1<2, \mathrm{P}<0.001 \\
1<3, \mathrm{P}<0.001 \\
2<3, \mathrm{P}=0.004\end{array}$ \\
\hline Social & $77.9 \pm 21.6$ & $83.0 \pm 16.1$ & $98.8 \pm 5.5$ & $27.32^{* * *}$ & $1<3, \mathrm{P}<0.001$ \\
\hline functioning & & & & & $2<3, \mathrm{P}<0.001$ \\
\hline Pain & $\begin{array}{l}71.2 \pm \\
31.4\end{array}$ & $83.0 \pm 20.7$ & $96.9 \pm 13.3$ & $17.25^{* * *}$ & $\begin{array}{l}1<3, \mathrm{P}<0.001 \\
2<3, \mathrm{P}=0.001\end{array}$ \\
\hline General health & $17.3 \pm 13.7$ & $19.8 \pm 16.5$ & $45.0 \pm 22.0$ & $33.25^{* * *}$ & $\begin{array}{l}1<3, \mathrm{P}<0.001 \\
2<3, \mathrm{P}<0.001\end{array}$ \\
\hline \multicolumn{6}{|c|}{$\begin{array}{l}{ }^{*} \mathrm{p}<0.05 ;{ }^{* *} \mathrm{p}<0.01 ;{ }^{* * * *} \mathrm{p}<0.001 ; \mathrm{SD}, \text { standard deviation; HRQOL, Health Related Quality Of Life; CCQ, Clinical } \\
\text { COPD Questionnaire (higher score means worse health status), SF-12, 12-item Short Form Health Survey (higher } \\
\text { score means better health status), Subgroup 1: high physical symptom cluster; Subgroup 2: moderate physical } \\
\text { symptom cluster; Subgroup 3: low physical symptom cluster. }\end{array}$} \\
\hline
\end{tabular}

Table 3 Comparison of HRQOL among three subgroups

\section{Prediction of the HRQOL}

As illustrated in Table 4, the linear regression revealed that the moderate physical symptom cluster (subgroup 2) had significantly lower CCQ score $(\beta=-0.367, \mathrm{t}=-4.077, \mathrm{p}<0.001)$ and significantly higher SF-12 scores $(\beta=0.355, \mathrm{t}=4.315, \mathrm{p}<0.001)$ than did the high physical symptom cluster (subgroup 1). Moreover, the low physical symptom cluster (subgroup 3) had significantly lower CCQ scores $(\beta=-0.837, \mathrm{t}=-9.310, \mathrm{p}<0.001)$ and significantly higher SF-12 scores $(\beta=0.909, \mathrm{t}=11.057, \mathrm{p}<0.001)$ than did the high physical symptom cluster (subgroup 1). The symptom cluster was able to explain $41.5 \%$ of the variance in the total scores of the CCQ (R2 = $0.415, \mathrm{~F}=48.279, \mathrm{p}<0.001)$ and $51.1 \%$ of the variance in the total scores of the SF-12 $(\mathrm{R} 2=0.511, \mathrm{~F}=71.054, \mathrm{p}<0.001)$, indicating that the higher physical symptom cluster had worse HRQOL.

\begin{tabular}{|c|c|c|c|c|c|c|c|}
\hline \multirow[b]{2}{*}{ Dependent variable } & \multirow{2}{*}{$\frac{\mathrm{R}}{\text { Square }}$} & \multirow{2}{*}{$\frac{\text { Adjusted }}{\text { R square }}$} & \multirow{2}{*}{$\frac{\mathrm{F}}{\text { change }}$} & \multicolumn{2}{|l|}{ Beta } & \multicolumn{2}{|l|}{$\mathrm{t}$} \\
\hline & & & & PHYS1 & PHYS2 & PHYS1 & PHYS2 \\
\hline \multicolumn{8}{|l|}{ CCQ } \\
\hline Symptom & 0.375 & 0.366 & $40.7^{5^{* * *}}$ & -0.410 & -0.815 & $-4.41^{* * *}$ & $-8.76^{* * *}$ \\
\hline Functional state & 0.275 & 0.264 & $25.74^{* * *}$ & -0.192 & -0.637 & -1.92 & $-6.36^{* * *}$ \\
\hline Mental state & 0.311 & 0.301 & $30.66^{* * *}$ & -0.399 & -0.748 & $-4.09^{* * *}$ & $-7.67^{* * *}$ \\
\hline Total score & 0.415 & 0.407 & $48.28^{* * *}$ & -0.367 & -0.837 & $-4.08^{* * *}$ & $-9.31^{* * *}$ \\
\hline \multicolumn{8}{|l|}{ SF-12 } \\
\hline Physical functioning & 0.269 & 0.259 & $25.09^{* * *}$ & 0.228 & 0.648 & $2.27^{*}$ & $6.45^{* * *}$ \\
\hline Role physical & 0.165 & 0.153 & $13.42^{* * *}$ & 0.051 & 0.439 & 0.47 & $4.09^{* * *}$ \\
\hline Role emotional & 0.255 & 0.244 & $23.24^{* * *}$ & 0.357 & 0.677 & $3.52^{* *}$ & $6.67^{* * *}$ \\
\hline Vitality & 0.536 & 0.529 & $78.52^{* * *}$ & 0.565 & 0.992 & $7.06^{* * *}$ & $12.38^{* * *}$ \\
\hline Mental health & 0.267 & 0.257 & $24.81^{* * *}$ & 3.677 & 3.606 & $4.20^{* * *}$ & $6.99^{* * *}$ \\
\hline Social functioning & 0.287 & 0.276 & $27.32^{* * *}$ & 3.368 & 3.303 & 1.52 & $6.32^{* * *}$ \\
\hline
\end{tabular}

Table. 4 to be Cont.... 


\begin{tabular}{|l|l|l|l|l|l|l|l|}
\hline Social functioning & 0.287 & 0.276 & $27.32^{* * *}$ & 3.368 & 3.303 & 1.52 & $6.32^{* * *}$ \\
\hline Pain & 0.202 & 0.191 & $17.25^{* * *}$ & 0.254 & 0.584 & $2.42^{*}$ & $5.56^{* * *}$ \\
\hline General health & 0.328 & 0.319 & $33.25^{* * *}$ & 0.054 & 0.609 & 0.56 & $6.32^{* * *}$ \\
\hline Total score & 0.511 & 0.504 & $71.05^{* * *}$ & 0.355 & 0.909 & $4.32^{* * *}$ & $11.06^{* * *}$ \\
\hline $\begin{array}{l}\text { Predictor: Symptom clusters (subgroup variables) } \\
{ }^{* p}<0.05 ; \\
\text { (higher score means worse health status), SF-12, 12-item Short Form Health Survey (higher score means better } \\
\text { health status), PHYS1, subgroup 2 moderate physical symptom cluster compared with subgroup 1 high physical } \\
\text { symptom cluster; PHYS2, subgroup 3 low physical symptom cluster compared with subgroup 1 high physical } \\
\text { symptom cluster. }\end{array}$
\end{tabular}

Table 4 Results from linear regression predicting HRQOL

\section{Discussion}

To our best knowledge, the present study was the first to attempt to identify subgroups based on symptom experiences in patients with COPD in Taiwan. We conducted this cross-sectional study using MSAS to describe the multidimensional symptom profile in patients with stable COPD.

In the present study, the symptoms with the highest prevalence were 'cough', followed by 'lack of energy' and 'dyspnoea'. Other symptoms included 'dry mouth' and 'pain'. Most previous studies have shown that dyspnoea, fatigue, lack of appetite, and anxiety are very severe primary symptoms of COPD, with the other symptoms including feeling drowsy, feeling anxiety, and feeling nervous $[13,21,36]$. However, this study has shown dyspnoea is not the most trouble some symptom, but the fatigue is the highest frequency, and more severity and distress than dyspnea (data not shown). This finding indicated that patients with COPD even their dyspnea are stable, they could be still troubled by fatigue. However, fatigue affects through the whole body and to be a natural consequence of COPD [37]. In addition, the present study revealed that pain was the distressful symptom that may be associated with aging and comorbidities. The previous studies indicated that comorbidity, several symptoms and quality of life were related to pain [38]. Furthermore, the present study revealed that more than $30 \%$ of the patients experiencedpsychological symptoms. Therefore, assessments for various systemic symptoms of COPD should be taken into account.

A previous study indicated that cough is a prominent and firstappearing respiratory symptom of chronic respiratory diseases, such as chronic bronchitis, asthma, or bronchiectasis [39]. Chronic cough is caused by smoking, bronchiectasis, and chronic bronchitis. According to statistics, at least $50 \%$ of the patients with COPD have cough symptoms, and least $30 \%$ of the patients with COPD are diagnosed with bronchiectasis by diagnostic chest CT. Cough and sputum production are also the predictors for acute exacerbation and progression of disease and are associated with the HRQOL [40]. Among the subjects of this study, mostly those with moderate COPD, the average FEV1\% value was $59.94 \pm 17.92$, and the majority of the patients were categorized under GOLD Group A (46\%). Moreover, $30.2 \%$ of the subjects were current smokers, and $58.3 \%$ had smoking experience. Smoking causes inflammation of the respiratory tract, which in turn causes the mucus cells and epithelial cells on the distal surface of the trachea to secrete increasing amounts of mucin [40].

Previous studies have shown that patients with severe-to-verysevere COPD had a dyspnoea prevalence as high as 53-94\% [13,21]. Among the study subjects, the majority $(56.1 \%)$ had moderate COPD (GOLD stage II), and a lower percentage (30.9\%) had severe and very severe COPD (GOLD stages III-IV), resulting in a lower dyspnoea prevalence $(58.99 \%)$ than among the patients with very severe COPD. The symptoms experiences of patients with COPD are complex. In addition to respiratory symptoms, they are plagued by other systemic symptoms [41].
In this study, we used the observed values from 18 physical symptoms as variables. Patients with COPD were divided into three subgroups according to cluster analysis. A previous study has documented significant differences in the average age, education level, and financial income among different subgroups of patients with COPD [42]. The findings of the present study are similar to those of Park et al [42]. Moreover, no significant differences in age, marital status, living conditions, and religious belief, as well as drug treatment patterns and comorbidities, were observed in the present study. These findings could be attributed to the fact that this study was conducted at two medical centres in the central region of Taiwan, and the restricted sampling area might have contributed to the small differences and lack of statistically significant differences. When compared with participants in subgroup 2 (moderate physical symptom cluster) and subgroup 3 (low physical symptom cluster), participants in subgroup 1 (high physical symptom cluster) had higher severity and distress due to physical symptoms and higher levels of psychological distress. When comparing the basic attributes, participantsin subgroup 1 had lower average education level than did those in subgroups 2 and 3 . These results are similar to those of a previous study showing that patients with high symptom distress have a lower level of education. Personal health knowledge is one of the factors that affect symptom experiences. Education is also a factor that has a potential impact on health literacy [42].

When comparing the symptom scores of dyspnoea, participants in subgroup 1 had higher symptom scores than did those in subgroups 2 and 3. The frequency of exacer bations was also higher in subgroup 1 than in subgroups 2 and 3 (data not shown). However, surprisingly, according to the degree of airflow obstruction in lung function, patients in subgroup 2 had the worst lung function (FEV1\%) among the three subgroups. Post-hoc comparisons showed no significant difference among the three subgroups.

Although significant differences were observed in FEV1/FVC, the physical symptom score of the correlation was weak, and no linear relationship was observed (data not shown). COPD is a multifaceted disease that can cause structural and functional changes to organs, especially the lungs. The degree of airflow obstruction alone cannot fully reflect the symptom burden and distress in patients with COPD. Furthermore, the use of FEV1 alone to determine dyspnoea, activity tolerance, or impaired HRQOL in patients with COPD results in poor correlation $[33,39]$.

The severity of disease is closely related to its symptoms. By using the physical symptom scores, we can distinguish patients with high physical symptoms from those with moderate and low physical symptoms, indicating that the more severe symptoms of dyspnoea are accompanied by other physical symptoms. The study also found that patients with high physical symptoms had an average of 1.54 comorbidities, which was significantly higher than that of patients with moderate and low physical symptoms (data not shown). Furthermore, the present findings also showed that patients with high physical symptoms had a higher proportion of hypertension and heart disease. Although these findings showed no statistically 
significant differences, the results should alert clinicians to the fact that the comorbidities of COPD might affect their patients' physical symptom experiences.

Regarding psychological distress, significant differences were observed in among the three subgroups. Patients with high physical symptoms had significantly higher psychological distress than did patients with moderate and low physical symptoms. This finding indicated that the patients with more severe physical symptoms of COPD had higher psychological distress, which was similar to the results of previous studies [43-45].

The present study revealed that different physical symptoms have significant differences in the severity of their effects on a patient'sHRQOL. Symptom clusters and the HRQOL (CCQ and SF12) showed significant medium-to-high correlations. This finding indicated that the more severe physical symptoms following the worsening of the HRQOL were closely related to the symptoms of COPD and its HRQOL; this finding was similar to those of previous studies $[38,46]$. In contrast, linear regression showed that symptom clusters may explain $41.5 \%$ and $51.5 \%$ of the variance in the CCQ and SF-12 scores, respectively, with regard to the HRQOL in the present study. This finding indicated that symptoms are powerful predictors of overall HRQOL in patients with COPD, which was a finding similar to those of previous studies $[9,47,48]$.

Overall, patients with high physical symptoms had the highest psychological distress and poorest HRQOL. This result was similar to those of studies on the symptom clusters of patients with cancer, which again points to the fact that patients with high physical symptoms have worse HRQOL and functional status than do patients with moderate and low physical symptoms $[15,50]$. In other words, the symptoms clusters can predict the HRQOL in patients with COPD. This finding supports the notion that symptom experiences affect the overall quality of life, and the HRQOL in turn affects the symptom clusters [51].

\section{Limitations}

This study had several limitations. First, the subjects were recruited from two out patient clinics; therefore, the results may not be generalizable to all levels of hospitals or all patients with COPD. Second, this study adopted a convenience sample to recruit 139 patients. Though the number had good statistical power $(>0.8)$, it may have had an effect on the number of symptom clusters. There is a dearth of clear guidelines about the number of samples required for cluster analysis, and there are no relevant statistical tests for cluster analysis. Moreover, in this study, the number of patients in the three subgroups was not equal. Subgroup 3 had the largest number of patients $55(39.6 \%)$, and the group with high physiological symptoms $(24.5 \%)$ had a small sample size. These patients may not be representative of the entire population. In addition, the homogeneity of the sample was high; there were no differences in the basic properties of the classes and attributes. Finally, although the subjects included in this study may represent the general attributes of patients at other study sites, especially in male-dominated areas, the findings cannot be extended to all patients with COPD considering the sex differences.

\section{Conclusion}

The symptom experiences of patients with COPD are complex. Three distinct subgroup clusters emerged on the basis of the analyses using 18 physical symptoms. Participants who had high levels of symptoms also had worse psychological distress and HRQOL than did those who had moderate and low levels of symptoms. Therefore, the symptom cluster subgroups were associated with psychological distress and the HRQOL. The symptomsare part of avicious cycle that affects every aspectof the patients' health, and results in the impairment of their overall health status and HRQOL. For patients with COPD, symptom assessment should be multidimensional and based on the concept of symptom clusters. The findings of this study provide a foundation for symptom management and nursing interventions to improve the health status and HRQOL of patients with COPD.

\section{Competing interests}

The authors of this paper declare no competing interests.

\section{Acknowledgements}

We are grateful to the participants of this study for their cooperation in this study and to the staff at the Pulmonary Clinic of the Department of Internal Medicine at National Taiwan University Hospital, Yunlin Branch, and Chung Shan Medical University Hospital, for their assistance.

\section{References}

1. World Health Organization (2020). The top 10 causes of death. Retrieved from https://www.who.int/news-room/fact-sheets/ detail/the-top-10-causes-of-death.

2. Weldam, SW., Lammers, JW., Decates, RL., Schuurmans, MJ. Daily activities and health-related quality of life in patients with chronic obstructive pulmonary disease: psychological determinants: a cross-sectional study. Health QualLife Outcomes. 2013;11:190.https://doi.org/10.1186/1477-7525-11-190

3. Global Initiative for Chronic Obstructive Lung Disease(2021). Global strategy for diagnosis, management, and prevention of COPD.http://www.https://goldcopd.org/2021-gold-reports/

4. Kessler, R., Partridge, MR., Miravitlles, M., et al. Symptom variability in patients with severe COPD: a pan-European crosssectional study. Eur Respir J. 2011;37:264-272.

5. Joshi, M., Joshi, A., Bartter, T. Symptom burden in chronic obstructive pulmonary disease and cancer. Curr Opin Pulm Med. 2012;18:97-103.DOI: 10.1183/09031936.00051110

6. Partridge, MR., Karlsson, N., Small, IR. Patient insight into the impact of chronic obstructive pulmonary disease in the morning: an internet survey. Curr Med Res Opin. 2009;25:2043-2048. DOI: $10.1185 / 03007990903103006$

7. $\mathrm{Hu}, \mathrm{J} .$, Meek, P. Health-related quality of life in individuals with chronic obstructive pulmonary disease. Heart Lung.2005;34:415-422.DOI: 10.1016/j.hrtlng.2005.03.008

8. Scano, G., Gigliotti, F., Stendardi, L., Gagliardi, E. Dyspnea and emotional states in health and disease. Respir Med. 2013;107:649-655.DOI: 10.1016/j.rmed.2012.12.018

9. Janssens, T., De Peuter, S., Stans, L., et al. Dyspnea perception in COPD: association between anxiety, dyspnea-related fear, and dyspnea in a pulmonary rehabilitation program. Chest. 2011;140:618-625.DOI: 10.1378/chest.10-3257

10. Jones, PW. Health status measurement in chronic obstructive pulmonary disease. Thorax. 2001;56:880-887.DOI: 10.1136/ thorax.56.11.880

11. Eckerblad, J., Todt, K., Jakobsson, P., et al. Symptom burden in stable COPD patients with moderate or severe airflow limitation. Heart Lung. 2014;43:351-357.DOI: 10.1016/j. hrtlng.2014.04.004

12. Theander, K., Hasselgren, M., Luhr, K., Eckerblad, J., Unosson, M., Karlsson, I. Symptoms and impact of symptoms on function and health in patients with chronic obstructive pulmonary disease and chronic heart failure in primary health care. Int $J$ Chron Obstruct Pulmon Dis. 2014;9:785-794. DOI: 10.2147/ COPD.S62563. eCollection 2014.

13. Walke, LM., Gallo, WT., Tinetti, ME., Fried, TR. The burden of symptoms among community-dwelling older persons with advanced chronic disease. Arch Intern Med. 2004;164:23212324. DOI: 10.1001/archinte.164.21.2321

14. Dodd, MJ., Miaskowski, C., Paul, SM. Symptom clusters and their effect on the functional status of patients with cancer. Oncol Nurs Forum. 2001;28:465-470. PMID: 11338755 
15. Kim, HJ., McGuire, DB., Tulman, L., Barsevick, AM. Symptom clusters: concept analysis and clinical implications for cancer nursing. Cancer Nurs. 2005;28:270-282. DOI: 10.1097/00002820-200507000-00005

16. Gold, JE., Piligian, G., Glutting, JJ., Hanlon, A., Frings-Dresen, MH., Sluiter, JK., Cluster analysis of symptoms among patients with upper extremity musculoskeletal disorders. J Occup Rehabil. 2010;20:526-536. DOI: 10.1007/s10926-010-9240-x

17. DeVon, HA., Ryan, CJ., Rankin, SH., Cooper BA. Classifying subgroups of patients with symptoms of acute coronary syndromes: A cluster analysis. Res Nurs Health. 2010;33:386397. DOI: $10.1002 /$ nur.20395

18. Bender, CM., Ergyn, FS., Rosenzweig, MQ., Cohen, SM., Sereika, SM. Symptom clusters in breast cancer across 3 phases of the disease. Cancer Nurs. 2005;28:219-225. DOI: 10.1097/00002820-200505000-00011

19. Miaskowski, C., Cooper, BA., Paul, SM., et al. Subgroups of patients with cancer with different symptom experiences and quality-of-life outcomes: a cluster analysis. Oncol Nurs Forum. 2006;33:E79-89. DOI: 10.1188/06.ONF.E79-E89

20. Blinderman, CD., Homel, P., Billings, JA., Tennstedt, S., Portenoy RK. Symptom distress and quality of life in patients with advanced chronic obstructive pulmonary disease. $J$ Pain Symptom Manage. 2009;38:115-123. DOI: 10.1016/j. jpainsymman.2008.07.006

21. Park, SK., Larson, JL. Multiple symptoms, functioning, and general health perception in people with severe COPD over time. Appl Nurs Res. 2016;29:76-82. DOI: 10.1016/j. apnr.2015.06.010

22. Stridsman, C., Mullerova, H., Skar, L., Lindberg, A. Fatigue in COPD and the impact of respiratory symptoms and heart disease--a population-based study.COPD. 2013;10:125-132. https://doi.org/10.3109/15412555.2012.728642

23. Victorson, DE., Anton, S., Hamilton, A., Yount, S., Cella, D. A conceptual model of the experience of dyspnea and functional limitations in chronic obstructive pulmonary disease. Value Health. 2009;12:1018-1025. DOI: 10.1111/j.15244733.2009.00547.x

24. Hasson, F., Spence, A., Waldron, M., et al. I can not get a breath: experiences of living with advanced chronic obstructive pulmonary disease. Int J Palliat Nurs. 2008;14:526-531. DOI: 10.12968/ijpn.2008.14.11.31756

25. Watz, H., Waschki, B., Meyer, T., Magnussen, H. Physical activity in patients with COPD. Eur Respir J. 2009;33:262-272. DOI: $10.1183 / 09031936.00024608$

26. Barnett, M. Chronic obstructive pulmonary disease: a phenomenological study of patients' experiences. J Clin Nurs. 2005;14:805-812. DOI: 10.1111/j.1365-2702.2005.01125.x

27. Espinosa de los Monteros, MJ., Pena, C., Soto, Hurtado, EJ., Jareno, J., Miravitlles, M. Variability of respiratory symptoms in severe COPD. Arch Bronconeumol. 2012;48:3-7. DOI: 10.1016/j.arbres.2011.07.004

28. Quanjer, PH., Stanojevic, S., Cole ,TJ., et al. Multi-ethnic reference values for spirometry for the 3-95-yr age range: the global lung function 2012 equations. Eur Respir J. 2012;40:1324-43. DOI: 10.1183/09031936.00080312

29. Portenoy, RK., Thaler, HT., Kornblith, AB., et al. The Memorial Symptom Assessment Scale: an instrument for the evaluation of symptom prevalence, characteristics and distress. Eur J Cancer. 1994;30A:1326-1336. DOI: 10.1016/0959-8049(94)90182-1

30. Cheng, KK., Wong, EM., Ling, WM., Chan, CW., Thompson, DR. Measuring the symptom experience of Chinese cancer patients: a validation of the Chinese version of the memorial symptom assessment scale. J Pain Symptom Manage. 2009;37:44-57.DOI: 10.1016/j.jpainsymman.2007.12.019
31. Polit, DF., Beck, CT. The content validity index: are you sure you know what's being reported? Critique and recommendations. Res Nurs Health. 2006;29;489-497. DOI: 10.1002/nur.20147

32. van der, Molen T., Willemse, BW., Schokker, S., ten Hacken, NH., Postma, DS., Juniper, EF. Development, validity and responsiveness of the Clinical COPD Questionnaire. Health Qual Life Outcomes. 2003;1:13. DOI: 10.1186/1477-7525-1-13

33. Lin, WC., Huang, TY., Liu, CY., Yeh, ML., Yu, CH., Hwang, SL. Validation of the Clinical COPDQuestionnaire in Taiwan. COPD. 2016;13:360-366. DOI: 10.3109/15412555.2015.1094456

34. Ware J, Jr., Kosinski, M., Keller, SD. A 12-Item Short-Form Health Survey: construction of scales and preliminary tests of reliability and validity. Med Care. 1996;34:220-233. DOI: 10.1097/00005650-199603000-00003

35. Ketchen, DJ Jr., Shook, CL. The Application of Cluster Analysis in Strategic Management Research: An Analysis and Critique. Strategic Manage J. 1996;17:441-458. https://www.jstor.org/ stable $/ 2486927$

36. Walke, LM., Byers, AL., Tinetti, ME., Dubin, JA., McCorkle, R., Fried, TR. Range and severity of symptoms over time among older adults with chronic obstructive pulmonary disease and heart failure. Arch Intern Med. 2007;167:2503-2508. DOI: 10.1001/archinte.167.22.2503

37. Stridsman, C., Lindberg, A., Skar, L. Fatigue in chronic obstructive pulmonary disease: a qualitative study of people's experiences. Scand J Caring Sci. 2014;28:130-138.DOI: 10.1111/scs. 12033

38. van Dam van Isselt EF, Groenewegen-Sipkema KH, Spruit-van Eijk M, Chavannes NH, de Waal MW, Janssen DJ, Achterberg WP. Pain in patients with COPD: a systematic review and meta-analysis. BMJ Open. 2014;4:e05898. DOI: 10.1136/ bmjopen-2014-005898

39. van der, Molen T., Miravitlles, M., Kocks, JW. COPD management: role of symptom assessment in routine clinical practice. Int J Chron Obstruct Pulmon Dis. 2013;8:461-471. DOI: 10.2147/COPD.S49392

40. Miravitlles, M. Cough and sputum production as risk factors for poor outcomes in patients with COPD. Respir Med. 2011;105:1118-1128. https://doi.org/10.1016/j. rmed.2011.02.003

41. Nussbaumer-Ochsner, Y., Rabe KF. Systemic manifestations of COPD. Chest. 2011;139:165-173. DOI: 10.1378/chest.10-1252

42. Park, SK., Meldrum, CA., Larson, JL. Subgroup analysis of symptoms and their effect on functioning, exercise capacity, and physical activity in patients with severe chronic obstructive pulmonary disease. Heart Lung. 2013;42:465-472. DOI: 10.1016/j.hrtlng.2013.08.008

43. McCathie, HC., Spence, SH., Tate, RL. Adjustment to chronic obstructive pulmonary disease: the importance of psychological factors. Eur Respir J. 2002;19:47-53. DOI: 10.1183/09031936.02.00240702

44. Eisner, MD., Blanc, PD., Yelin, EH., Katz, PP., Sanchez, G., Iribarren, C. Influence of anxiety on health outcomes in COPD. Thorax. 2010;65:229-234. DOI: 10.1136/thx.2009.126201

45. Iguchi, A., Senjyu, H., Hayashi, Y., et al. Relationship between depression in patients with COPD and the percent of predicted FEV(1), BODE index, and health-related quality of life. Respir Care. 2013;58:334-339. DOI: 10.4187/respcare.01844

46. Tsiligianni, I., Kocks, J., Tzanakis, N., Siafakas, N., van der, Molen T. Factors that influence disease-specific quality of life or health status in patients with COPD: a review and meta-analysis of Pearson correlations. Prim Care Respir J. 2011;20:257-268. DOI: $10.4104 /$ pcrj.2011.00029 
47. Janssen, DJ., Franssen, FM., Wouters, EF., Schols, JM., Spruit MA. Impaired health status and care dependency in patients with advanced COPD or chronic heart failure. Qual Life Res. 2011;20:1679-1688. DOI: 10.1007/s11136-011-9892-9

48. Siebeling, L., Musoro, JZ., Geskus, RB., Zoller, M., Muggensturm, P., Frei, A. Prediction of COPD-specific health-related quality of life in primary care COPD patients: a prospective cohort study. NPJ Prim Care Respir Med. 2014;24:14060.https://doi.org/10.1038/npjpcrm.2014.60

49. Kimble, LP., Dunbar, SB., Weintraub, WS., McGuire, DB., Manzo, SF., Strickland, OL. Symptom clusters and health-related quality of life in people with chronic stable angina. $J A d v$ Nurs. 2011;67:1000-1011. DOI: 10.1111/j.1365-2648.2010.05564.x
50. Husain, A., Myers, J., Selby, D., Thomson, B., Chow, E. Subgroups of advanced cancer patients clustered by their symptom profiles: quality-of-life outcomes. $J$ Palliat Med. 2011;14:1246-1253. DOI: 10.1089/jpm.2011.0112

51. Lenz, ER., Pugh, LC., Milligan, RA., Gift, A., Suppe, F. The middle-range theory of unpleasant symptoms: an update. ANS Adv Nurs Sci. 1997;19:14-27. DOI: 10.1097/00012272199703000-00003 